\title{
INVESTMENT COST MODEL IN BUSINESS PROCESS INTELLIGENCE IN BANKING AND ELECTRICITY COMPANY
}

\author{
Arta Moro Sundjaja \\ Information System Department, School of Information System, Bina Nusantara University, \\ Jl. K.H. Syahdan No. 9, Palmerah, Jakarta Barat, 11480 \\ asundjaja@binus.edu
}

\begin{abstract}
Higher demand from the top management in measuring business process performance causes the incremental implementation of BPM and BI in the enterprise. The problem faced by top managements is how to integrate their data from all system used to support the business and process the data become information that able to support the decision-making processes. Our literature review elaborates several implementations of BPI on companies in Australia and Germany, challenges faced by organizations in developing BPI solution in their organizations and some cost model to calculate the investment of BPI solutions. This paper shows the success in BPI application of banks and assurance companies in German and electricity work in Australia aims to give a vision about the importance of BPI application. Many challenges in BPI application of companies in German and Australia, BPI solution, and data warehouse design development have been discussed to add insight in future BPI development. And the last is an explanation about how to analyze cost associated with BPI solution investment.
\end{abstract}

Keywords: Business process intelligence, business process management, investment cost model

\section{INTRODUCTION}

Nowadays the numbers of top management in a company facing many strategic problems that required reliable information about company performance to develop business solution in short time. Business intelligence has that capability to perform data mining and statistical analysis. Business process intelligence is an integrated tool that support and maintaining the business process so the top management can ensure the process execution quality. The objectives of managing performance are producing and controlling the performance system that is used by the organization. From the management perspective, performance management system consists of planning, implementation, evaluation, training, and reward management (Wade \& Recardo, 2001). The characteristics of corporate performance management (CPM) are process-oriented, goal and metric oriented, methodology support, IT support. Process CPM was design based on organization procedures and integrated with defined corporate strategic process, cascading the strategic into business process, analyze the strategy and process implementation, and formulate appropriate decisions. In supporting measurement process and maintaining the business process, top management needs a clear objective so that can be cascade into strategy and metric development to measure and control the process. Performance management strategy such as balanced scorecard, intellectual capital or value-based management is a model for connecting the strategic goal and the measurement metric so the management can use it as measure and control the organization performance.

Performance management strategy is needed to integrate the strategic formulation, the business process development, and the business process execution. Information technology role in 
performance management is very important; top management cannot measure and analyze the company performance without integration between IT and performance management system. Balanced scorecard implementation in the organization as a performance management tool can contribute major performance improvement compared with a traditional organization (Andersen, Cobbold, and Lawrie, 2003; Davis and Albright, 2004; Wade and Recardo, 2001). In supporting performance measurement process, business process automation implementation in the organization is optimizing business process and operational function integration. A business process is supported by more applications such as customer relationship management (CRM) application to support interaction between company and customer, service management (SM) application to coordinate service requests with billing system (BS) application for billing, and human resource management (HRM) to manage employees.

In supporting the business process that aligns with organization strategy, all application functions need to be integrated with the business process procedure. By using the business intelligence technology, data from all business applications can be integrated into decision-making repository, save the data, and access the data(Watson, 2009). Business intelligence technology implementation also helps the management to compare data from various business process performances to improve business performance. Business Process Intelligent concept is beginning to be developed for the collection and reconciliation of all operational data of a particular business process that enable management in process performance measurement and identification of opportunities for process improvement.

This literature review provides insight for an organization to get better understanding through the case study of business process intelligence implementation, challenge in business process intelligence implementation and the cost model for calculating the investment of business process intelligence.

\section{METHODS}

To explore the BPI concept in this research, all published article about business process intelligent implementation, challenge in business process intelligent development and implementation, and cost model for calculating the business process intelligent implementation in Science Direct and Proquest were searched. This literature review tries to explore the business process intelligence implementation, challenge in business process intelligence implementation, and cost model to calculate the Business process intelligence investment soother researcher can use it as guidance in implementing the business process intelligence. Case study is used to explain the business process intelligence implementation, challenge in business process intelligence implementation and cost model in business process intelligence implementation. In this paper, the topics are divided into three sections. The first section discusses business process Intelligence (BPI) applications in companies (Genrich et al., 2008; Hawking and Sellitto, 2015). The second section discusses challenges in BPI application(Genrich et al., 2008; Grigori et al., 2004; Mansmann, Neumuth, and Scholl, 2007). The last section discusses cost model for BPI investment measurement (Wade and Recardo, 2001).

\section{RESULTS AND DISCUSSIONS}

In the first section, business process intelligence implementation in several companies is discussed. The implementation of process mining can contribute many benefits to the business; not all companies already implemented it in their operational level. Genrich et al., (2008) explain that more organizations such as German bank, German insurance company, and Australia utility company. 
Those organizations use the business process data for performance evaluation to gather better business insight (Genrich et al., 2008). The research objective is to analyze single transaction in multi-input and multi-output to understand the deficit in process performance. The research objects are securities settlement and clearing process. This research cooperates with Commerz bank AG using bank's operational data. This research introduces data envelopment analysis (DEA) approach. DEA approach is a non-parametric and non-stochastic efficiency measurement method. DEA is used as performance evaluation method to compare different decision-making unit with the best observation practices. Researchers apply DEA in business process level to identify inefficient business process patterns based on resources transformation (process, financial data, and human resources) into the result (quality, risk, cost, etc.). Based on the study, it can be summarized that bank in the financial industry faces a fierce competition such as high regulation from the government, customer demand more service, and product. Based on those facts, process management is influenced by complexity in service and product and missing efficiency standard. This condition causess a gap between inputs factor and results from the transaction security in various cases. Therefore, DEA method is an appropriate method for measuring process performance in banks. Besides, it was found that there is no agreement and definition of a business process in a company or industry level. The agreements like how to calculate transactions or comparisons across companies to assist in measuring the performance of the business process.

Top management is required to make an effective decision in designing the business process and allocating the resource; this condition required a reliable operational data that obtained timely and accurate. An insurance company in Germany wants to improve the decision-making process that includes information related to business processes. The top management initiates business process intelligent project to response the inconsistent information caused by the different system to retrieve the information and saving customer information and corporate rules. Those problems caused by the data source and mining method were aggregated in the wrong way. Activity-based costing method requires information about the resource, cost, time, and frequency of activity. The problem exists because the existing business process mapping system fails to provide the number of processes and activities directly estimated from the data in the company's mainframe systems. All the data for calculating the activity based costing already defined but the mainframe systems only record the time of each transaction so that the time required to process an activity cannot be calculated. The management decided that implementation of electronic document management system can solve the problems; so that the audit trail information can be stored in the system and can be used for calculating activity based costing. The re-engineering of infrastructure triggered by the top management and supported by the senior management that resulting a major positive impact on overall business process performance.

Electricity failure during and after a storm and it takes time to fix the problem. It causes a major problem in customer satisfaction for electric utilities in Australia. The study was conducted on electric utilities owned by the state that have responsibility for the distribution and operation of the electrical network about $10,000 \mathrm{~km}$ to support approximately 600.000 users. This research has focused on the interaction and performance of call center services, operations center, and field personnel in the event of a storm and unplanned network failure. The initial goal of this project is to understand and mitigate the root causes of the problem of communication between the three groups in the unexpected accident. The problems such as high volume of data during outages, low data (customer information, outages description, type of deterioration) quality produced by several systems and synchronization of data from network operation center, contact center, and field crew. Those problems become a challenge for the system to examine the data associated with the electricity failure caused by the storm. First, the analyst must understand the cause of the problem such as increasing outages and communication problems between parts. Lesson learned gathered by the organization is isolated transaction flow and focus on efficiency or optimal performance for the customer. 
According to Hawking and Sellitto (2015), utilities company in Australia faced a challenge in supplied the electricity to their customer via network infrastructure that required regular maintenance. The IT department deploys various information systems to support the maintenance program and monitoring the cost of maintenance the infrastructure. After a couple of years later, the information system developed could not answer the development and the business needs of the company. The business unit and IT department faced data and business integration issue so that the system maintenance cost increased. Finally, the top management decided to implement the ERP system for data structure standardization, and business process integration and business intelligence for information delivery and analysis improvement in Australian Utilities Company was very helpful in top management decision making. In 2008, the company finally developed the Information Management Strategy to accommodate Business Intelligence Implementation. The main goal of this strategy was the company had one version of reliable and trusted data for helping the top management in making the right decision. The Information Management Strategy consists of four aspects, as follow: information hierarchy, application strategy or business intelligence architecture, reporting strategy, and governance model. Information hierarchy was designed based on the user requirement. The application strategy was designed to provide the Business Intelligence environment to generate high quality and consistent data through a system that has been developed so that the users can develop right decisions. Reporting strategy was designed based on information that required by the user. The governance model was identified based on governance roles and responsibilities within the company, so that enhance the link between information technology and business units.

It is concluded that the importance of business process implementation in several companies can produce an effective decision making to solve the strategic and operational level. In the second section, challenge in the implementation of business process intelligence development is discussed. Grigori et al. (2004) stated that there were some challenges in BPI solution development. (1) Understanding BPI architecture identification, BPI function production (analysis, prediction, observation, controlling, and optimization) and BPI implementation knowledge to achieve organization objectives. (2) Able to identify the concept and metric for analyzing the business process at business and qualitative level. (3) Able to develop or use the application to get the knowledge without write any programming commands. (4) Able to understand the interaction between business process management systems (BPMS) and user to produce a report and make a right decision in a critical situation.

Mansmann et al., (2007) explained that there were some challenges for data warehouse designer in BPM contexts, such as the many-to-many relationship between facts and dimensions, heterogeneity when inserting the facts, fact exchange functions, and dimension. Genrich et al.,( 2008) stated that there were some challenges in BPI implementation at German Bank. (1) Security of the applications in every process function (data enrichment, confirmation, settlement, clearing and booking). (2) Functional focused on applications development and not focused on the process. (3) There is no documentation on functional and technical; this problem is caused by senior staffs who manage the application over the years. (4) Each application uses an individual reference; there are overlapping references and thus requiring the mapping of the unique references across the application. (5) Need more time to select the right database.

Genrich et al., (2008) stated that there were more challenges in BPI implementation at German Insurance Company. (1) No reliable data sources to provide information to the top management when they are required making a decision. (2) Information provided by the existing systems was not accurate because of many data sources and inappropriate combination technique. (3) Mainframe systems only record the time per transaction, resulting the management to cannot calculate the processing time consuming for all processes.

Genrich et al., (2008) stated there were challenges in BPI implementation at Australian utility company. (1) High data volume generated during the electricity failure, the entire process of 
identifying trends in the electricity failure data analysis that requires strenuous effort. (2) In some systems, not all the data is stored properly, poor data quality at the time of the electricity failure. Data such as customer information, failure information, data field associated with a qualitative description of the outage.

Based on the challenge that already explained, it can be concluded that the classic problem faced by management is alignment between the network operations center data, field officer data, and contact center data.

The last section of this paper discusses cost model to calculate business process implementation to measure the investment cost. Mutschler, Bumiller, and Reichert(2005) explained that the company is forced to optimize business and services processes regularly, in the context of the information systems alignment with a focus on process is important. The use of BPI solutions indeed offers promising results, but the company will consider the investment and profits if you want to implement such solution. Before considering factors that affect the cost and benefit approach of the BPI, Figure 1 illustrates the conceptual reference architecture BPI.

This architecture consists of three tiers, such as data integration, main function, and visualization. In data integration tiers, process warehouse stores the application data and generated control during the real-time process. It also keeps a process warehouse the estimated value of the reference (derived from the simulation process) so that, the delta analysis can be done. In the data loading process into the data warehouse, data obtained from various information systems supporting business processes through the ETL (extract, transform, and load). The data warehouse is located in process execution event logs, event execution logs (audit trail) is sufficient level of detail varies from general to detail, depending on the use of information systems. In practice, the integration of log data is quite challenging. In the main function tier, BPI must be able to measure and evaluate the performance of the process. Unit processing must be aggregate and calculate the key performance indicator (KPI) based on data provided by process warehouse. Process mining component responsible for automating the modeling process model (optimal) based on log data. Components provide support for the administration of access rights. In visualization component provides set of presentation elements (traffic light or graphic) to designing needed presentation by the user (dashboard).

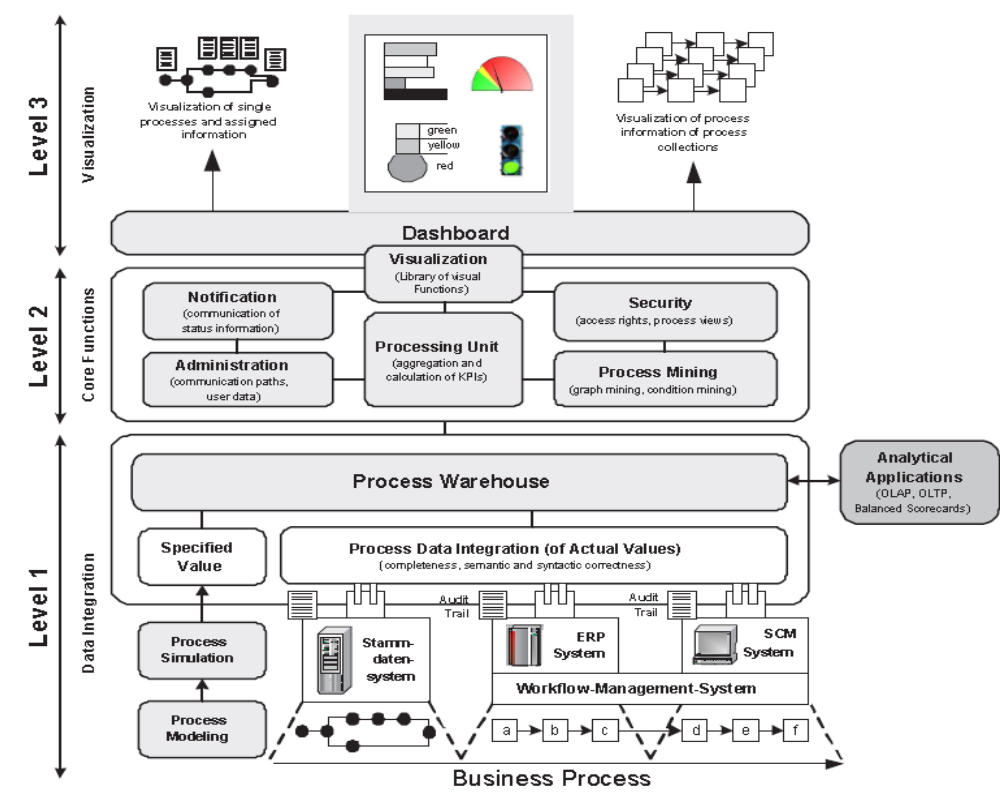

Figure 1 Conceptual Reference of BPI Architecture Source: (Mutschler et al., 2005) 
In analyzing, the costs associated with BPI investment can be divided into two cost scenarios. The first cost scenario is the total cost of ownership of BPI. As it can be seen in Figure 2, analysis of the total cost of ownership of BPI can be divided into direct costs and indirect costs. Cost can be divided into four categories: BPI software, BPI hardware, BPI support, and BPI customizing. Indirect costs arise due to a decrease in productivity, cause of indirect costs is self-support of users, informal learning activities, and personal customizing. It can be concluded that calculating direct cost is easier than indirect cost.

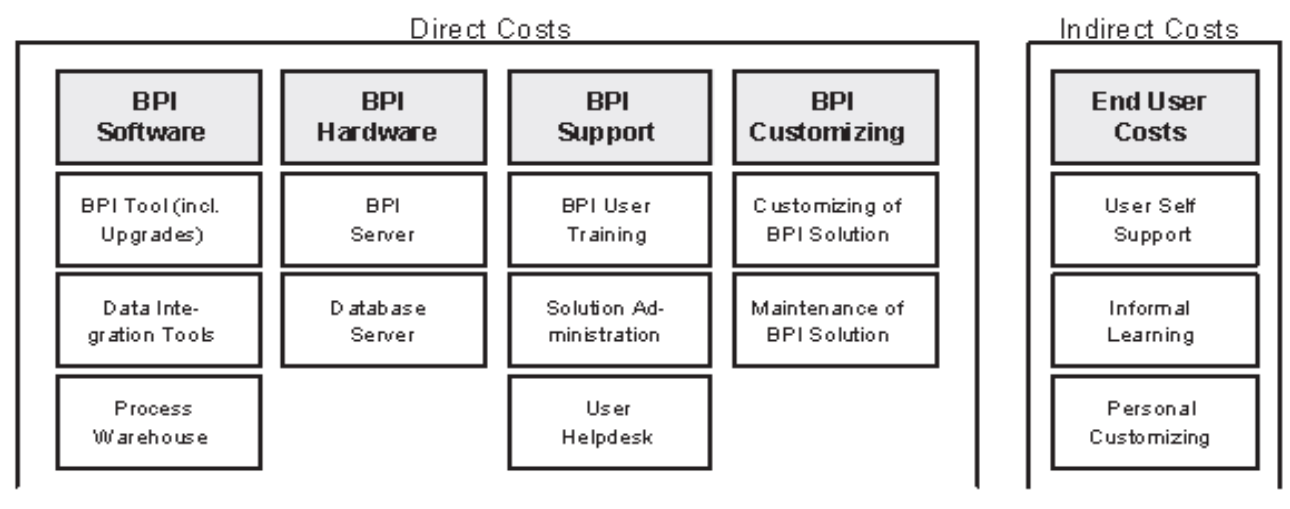

Figure 2 Classification of BPI Investment Cost Source: (Mutschler et al., 2005).

In practice, the complexity of the BPI investment scenario could affect exponentially in increasing the cost variation. $\mathrm{W}$ is the economies of scale or scenarios with increasing complexity BPI. In cost model, if $\mathrm{W} \leq 1$, then the complexity is high, and investment BPI shows economies of scale. If the complexity of the scenario increased two-fold BPI, BPI investment costs to be more than doubled. $\mathrm{W}=1$ describes the economic scenario with BPI standards and uneconomically can be balanced. If $\mathrm{W}$ $\geq 1$, the complexity is low BPI and BPI shows uneconomically investment. Cost model to calculate the BPI investment can be seen in Figure 3.

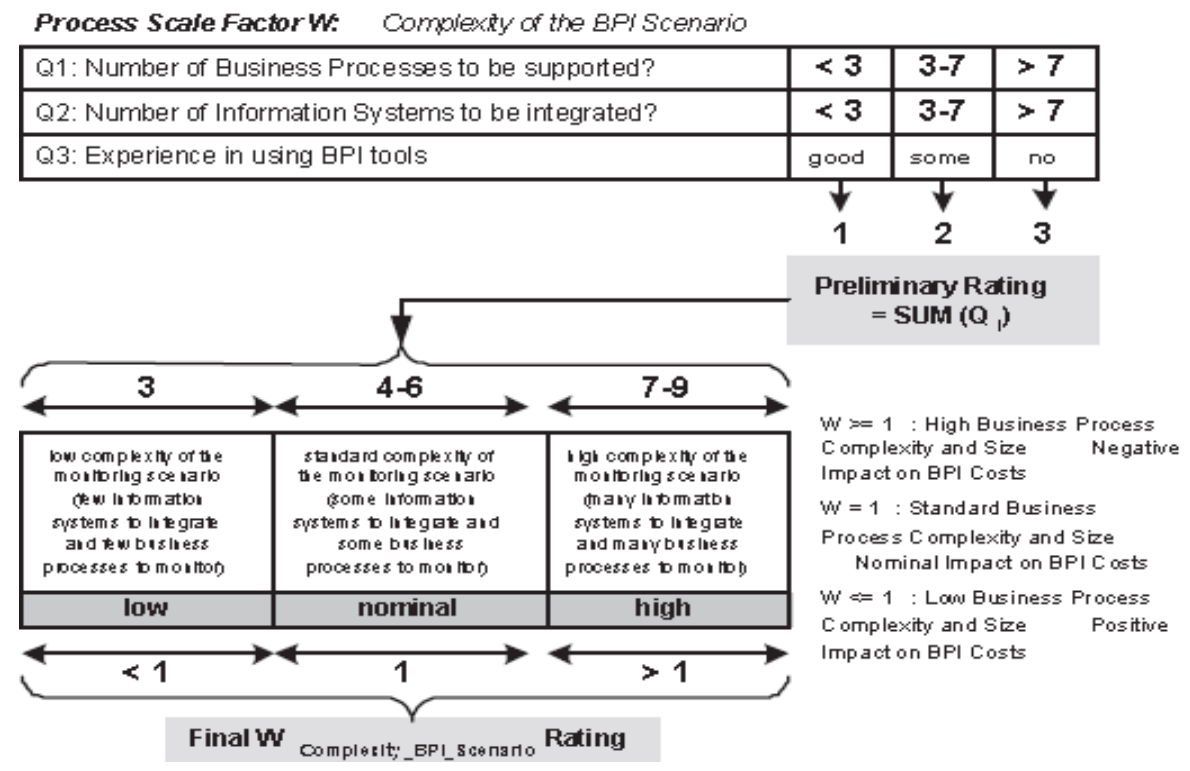

Figure 3 Cost Model for Calculating BPI Investment.

Source: (Mutschler et al., 2005). 
The second cost scenario is impacts from BPI application development. The cost algorithm model based on the mathematical formula for predicting impacts of technology application improvement on cost and schedule lifecycle can be seen as follow.

$$
\text { Effort (person months })=A *(\text { size }) B * E M
$$

A represents application system quantity that measurable using line of code, functions points or object points. B represents exponential scale factor for calculating relativity of economical or not economical scale from quantity increasing of a system project. EM is a collection of linear effort multipliers addition.

The model above can cover a fairly large area in an application project; the problem is that the model does not represent probabilities of impacts from BPI. So the suggested effort multiplier would be EMbpi, as it can be seen in Figure 4.

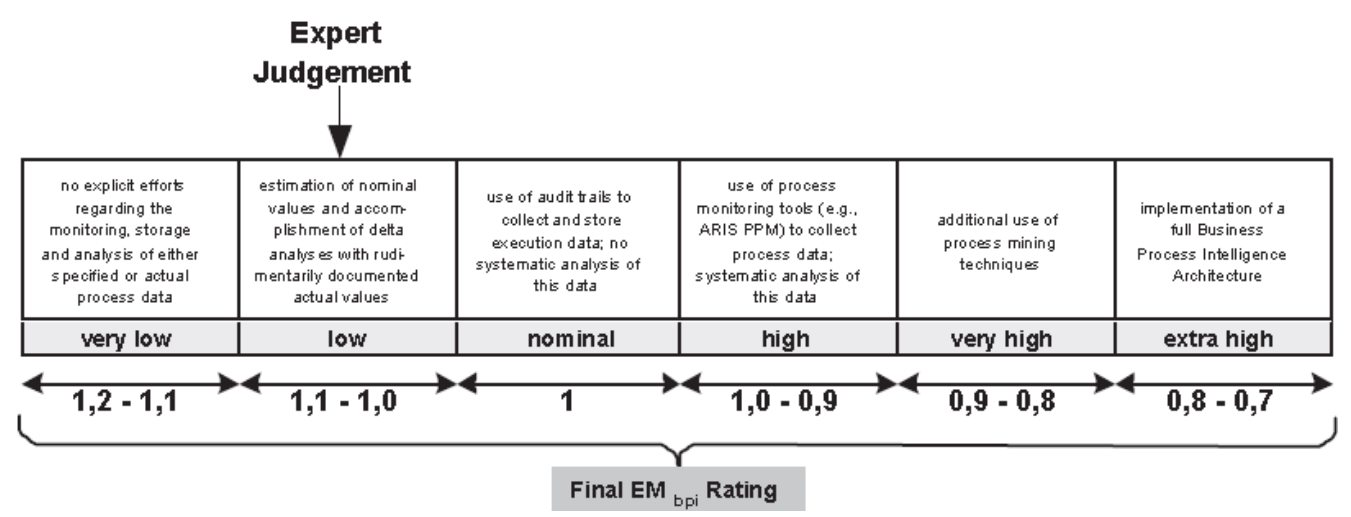

Figure 4 Assessment for Cost Trigger of BPI. Source: (Mutschler et al., 2005).

\section{CONCLUSIONS}

This article describes that BPI applications of companies in German and Australia spotted many challenges in BPI development and introduction of two cost models for analyzing two aspects related to BPI investment. This discussion about success in BPI application of banks and assurance companies in German and electricity work in Australia aims to give a vision about the importance of BPI application. Many challenges in BPI application of companies in German and Australia, BPI solution, and data warehouse design development have been discussed to add insight in future BPI development. And the last is an explanation about how to analyze cost associated with BPI solution investment.

This article has some limitations; there are only three companies that already implement business process intelligent which are reviewed. It is suggested to review more companies that already implement business process intelligent in order to provide more examples about the successful business process intelligence and give a better insight about challenge in business intelligence process.

The future research is how to use the cost model in real world scenario using a case study, how to classify the financial statement in a company such as balance sheet and income statement into business process intelligence cost model so the top management can analyze the cost and benefit of implementing business process intelligence in their company. 


\section{REFERENCES}

Andersen, H., Cobbold, I., \& Lawrie, G. (2003). Balanced Scorecard Implementation in SMEs: Reflection in Literature and Practice. In 2GC Conference (pp. 1-9). Copenhagen: 2GC Limited. Retrieved from http://www.csudh.edu/dearhabermas/smebal01.pdf

Davis, S., \& Albright, T. (2004). An investigation of the effect of Balanced Scorecard implementation on financial performance. Management Accounting Research, 15(2), 135-153. http://doi.org/10.1016/j.mar.2003.11.001

Genrich, M., Kokkonen, A., Moormann, J., Muehlen, M. Zur, Tregear, R., Mendling, J., \& Weber, B. (2008). Challenges for business process intelligence: Discussions at the BPI workshop 2007. Lecture Notes in Computer Science (Including Subseries Lecture Notes in Artificial Intelligence and Lecture Notes in Bioinformatics), 4928 LNCS, 5-10. http://doi.org/10.1007/978-3-540-78238-4_2

Grigori, D., Casati, F., Castellanos, M., Dayal, U., Sayal, M., \& Shan, M.-C. (2004). Business process intelligence. Computers in Industry, 53(3), 321-343.

Hawking, P., \& Sellitto, C. (2015). Business intelligence strategy: a utilities company case study. Business Intelligence: Concepts, Methodologies, Tools, and Applications: Concepts, Methodologies, Tools, and Applications, 305-315.

Mansmann, S., Neumuth, T., \& Scholl, M. H. (2007). OLAP Technology for Business Process Intelligence: Challenges and Solutions. Data Warehousing and Knowledge Discovery, 4654 LNCS, 111-122. http://doi.org/10.1007/978-3-540-74553-2_11

Mutschler, B., Bumiller, J., \& Reichert, M. (2005). An Approach to quantify the Costs of Business Process Intelligence. Int'l. Workshop on Enterprise Modelling and Information Systems Architecture (EMISA), 152-163. Retrieved from http://dbis.eprints.uni-ulm.de/270/

Wade, D., \& Recardo, R. J. (2001). Corporate performance management how to build a better organization through measurement-driven strategic alignment. Boston: ButterworthHeinemann. Retrieved from http://public.eblib.com/choice/publicfullrecord.aspx?p=535001

Watson, H. J. (2009). Tutorial: Business intelligence - Past, present, and future. Communications of the Association for Information Systems, 25(1), 487-510. 